\section{Well-trained generalists can help improve surgical capacity at district hospitals}

To the Editor: The evaluation of the surgical outreach programme to district hospitals in Sisonke Health District (SHD), KwaZulu-Natal, South Africa (SA), recently published in the SAMJ demonstrates an admirable commitment to improving district health services. ${ }^{[1]}$ While the authors documented a large number of flying hours and kilometres travelled and 2160 operations performed over a 6-month period in the four district hospitals, it is difficult to determine what the impact of the surgical outreach was on the number and range of operations performed.

They state that 'surgical outreach is proposed as a strategy to increase the surgical output of district hospitals. Although our programme has succeeded in delivering point-of-care need it has been less successful in building operative capacity. Solutions such as enhanced training programmes in district hospitals v. bypassing district hospitals and offering surgical services only at regional centres are offered. However, emergency surgery, such as caesarean sections, cannot be centralised in this way without a negative impact on maternal and other mortality. The authors show no awareness of the potential contribution of well-trained generalists such as family physicians and clinical associates to increasing access to comprehensive services in the district. ${ }^{[2]}$

Family physicians are expert generalists trained in the same model of a 4-year MMed degree programme as other specialists. This new specialty was approved in 2007 and started graduating family physicians in 2011. They are specifically trained to work as generalists in the district, including the district hospital. ${ }^{[3]}$ The list of surgical skills that are part of their training programme incorporates all the emergency and common obstetric, surgical and orthopaedic procedures appropriate to the district hospital. ${ }^{[4]}$ This list is about to be revised 5 years after a national consensus was agreed. In some provinces, such as the Western Cape, the goal is to place at least one such family physician at each district hospital, where they will increase the surgical output and improve operative capacity. ${ }^{[5]}$ The new mid-level doctor, known as the associate clinician, has also been specifically trained to work at the district hospital, and these graduates are now entering the system.

Part of the solution to improving surgical as well as other services at district hospitals may therefore lie in an approach that combines the placement of full-time family physicians and associate clinicians at district hospitals with periodic outreach from surgical specialists, who should also enhance the training of these new cadres of health workers.

\section{Bob Mash}

Department of Family Medicine and Primary Care, Faculty of Health Sciences, Stellenbosch University, Tygerberg, Cape Town, South Africa

rm@sun.ac.zo

\footnotetext{
Clarke DL, Aldous C. Surgical outreach in rural South Africa: Are we managing to impart surgical skills? S Afr Med J 2014;104(1):57-60. [http://dx.doi.org/10.7196/SAMJ.7252]

Howe AC, Mash RJ, Hugo JFM. Developing generalism in the South African context. S Afr Med J 2. Howe AC, Mash RJ, Hugo JFM. Developing generalism in the
2013;103(12):899-900. [http://dx.doi.org/10.7196/SAMJ.7509]

3. Couper I, Mash B, Smith S, Schweitzer B. Outcomes for family medicine postgraduate training in South Africa. S Afr Fam Pract 2012;54(6):501-506.

4. Couper ID, Mash B. Obtaining consensus on core clinical skills for family medicine training. S Af Fam Pract 2008;50(6):41.

5. Mash B. Reflections on the development of family medicine in the Western Cape: A 15-year review. S Afr Fam Pract 2011;53(6):557-562.
}

Clarke and Aldous respond: The problem of ensuring delivery of adequate surgical care in the rural districts of SA is a complex one, and the solutions will not be simple. We have undertaken quite an extensive review of the quality of trauma and acute surgical care in SHD and have identified a number of deficits. ${ }^{[1-3]}$ It seems likely that this situation may exist in other rural health districts as well. Addressing these deficits will require a multifaceted approach, and the well-trained competent generalist will be central to any such quality improvement programmes. The idea of formalising a training programme that can produce these competent generalists is a good one, and needs to be encouraged and supported.

\section{L Clarke}

Pietermaritzburg Metropolitan Trauma Service and Department of Surgery, Nelson Mandela School of Medicine, College of Health Sciences, University of KwaZulu-Natal, Durban, South Africa damianclar@gmail.com

\section{Aldous}

School of Clinical Medicine, Nelson Mandela School of Medicine,

College of Health Sciences, University of KwaZulu-Natal, Durban, South Africa

1. Clarke DL, Aldous C, Thomson SR. The implications of the patterns of error associated with acute trauma care in rural hospitals in South Africa for quality improvement programs and trauma education. Injury 2014;45(1):285-288. [http://dx.doi.org/10.1016/j.injury.2013.04.011]

2. Clarke DL, Kong VY, Handley J, Aldous C. A concept paper: Using the outcomes of common surgical conditions as quality metrics to benchmark district surgical services in South Africa as part of a systemic quality improvement programme. S Afr J Surg 2013;51(3):84-86. [http://dx.doi.org/10.7196/SAJS.1476]

3. Kong VY, Van der Linde S, Handley J, Aldous C, Clarke DL Quantifying the disparity in outcome between urban and rural patients with acute appendicitis in South Africa. S Afr Med J 2013:103(10):742745. [http://dx.doi.org/10.7196/SAMJ.7109]

S Afr Med J 2014;104(5):323. DOI:10.7196/SAMJ.7897 